\title{
The Robustness and Sustainability of Port Logistics Systems for Emergency Supplies from Overseas
}

\author{
Yanyu Chen $\mathbb{D D}^{1}{ }^{1}$ Wenzhe Zheng, ${ }^{1}$ Wenbo $\mathrm{Li}^{1}{ }^{1}$ and Yimiao Huang ${ }^{2}$ \\ ${ }^{1}$ College of Economics and Management, Zhejiang Normal University, Jinhua 321004, Zhejiang, China \\ ${ }^{2}$ School of Public Administration, Changchun University of Technology, Changchun 130012, Jilin, China \\ Correspondence should be addressed to Yanyu Chen; tyler4585@zjnu.edu.cn
}

Received 30 May 2020; Revised 14 July 2020; Accepted 8 August 2020; Published 1 September 2020

Academic Editor: Sang-Bing Tsai

Copyright (c) 2020 Yanyu Chen et al. This is an open access article distributed under the Creative Commons Attribution License, which permits unrestricted use, distribution, and reproduction in any medium, provided the original work is properly cited.

\begin{abstract}
When the epidemic comes, in addition to eliminating people's panic, quickly enacting corresponding laws and implementing corresponding policies, and isolating infected people, providing emergency supplies are of course essential. The purpose of this article is to study the robustness and sustainability of the port logistics system for outbreak emergency supplies from overseas. This paper analyzes the sustainable development capability of the port logistics system for outbreak emergency supplies from overseas and formulates response strategies and robust collaborative optimization methods. The optimized and robust system is obtained through formula derivation and analysis, which realizes the coordinated optimization of emergency logistics infrastructure positioning and emergency rescue vehicle path positioning and minimizes the economic loss caused by the outbreak. Research data show that the shortest path can be planned between each material supply location. The research results show that the proportion of demand fluctuations during the outbreak is $6.5 \%$, the time window needs to be controlled between 0 and 600 , and the robustness and sustainability of the port logistics system have saved the time of the entire process by about $45 \%$, greatly optimizing the delivery route and delivery time. The robustness of the logistics system can be widely used in emergency events.
\end{abstract}

\section{Introduction}

The logistics industry is known as the "third profit source," and the logistics industry has now become an indispensable strategic industry for development at home and abroad [1]. As consumption in modern society begins to diversify, material production begins to soften, and economic circulation begins to become more efficient; everyone's requirements for the level and quality of logistics services begin to increase. Therefore, the quality of logistics services is extremely important in the future development of the logistics industry, that is, to provide customers with highquality products at a specified time and a specified location in an appropriate quantity and at a price generally acceptable to the public [2].

With the deepening of China's internationalization, domestic and foreign exchanges are becoming more frequent, and the port logistics system has developed by leaps and bounds. However, in recent years, major foreign epidemics have occurred frequently. Port logistics is the place most affected by overseas epidemics. Being able to carry out the exchange of port logistics without affecting the production and life of our people requires serious consideration. This also requires us to study the robustness and sustainability of the port logistics system for outbreak emergency materials from overseas. At present, China's emergency logistics planning system in the organization link is not yet perfect. Although each department of the government has its own emergency plan, the plans between the departments cannot be well communicated and communicated [3]. This has led to the inability to effectively establish effective communication in the face of overseas epidemics, to prevent the overseas epidemic from being introduced into China in port logistics in time and ultimately to avoid the paralysis of port logistics, which requires us to deal with the epidemic from overseas. The robustness and sustainability of the port 
logistics system of emergency supplies are carefully studied to ensure the production and life of our people [4].

In the era of rapid development of science and technology in our country, once the epidemic situation comes, our country must respond within the first time and timely plan the human and material resources for rescue. After purchasing emergency supplies in large quantities abroad, they should be promptly transported back to the epidemic location for support. At this time, the powerful port logistics system directly determines the progress of effective epidemic control $[5,6]$. In our country, if the logistics system presents obstacles in any logistics node such as outbound, transportation, and transshipment, a small one will reduce the distribution efficiency and a large one may lead to the paralysis of the entire logistics system. This paper analyzes the sustainable development capabilities of the port logistics system for outbreak emergency materials from overseas and formulates coping strategies and robust collaborative optimization methods. The optimized and robust system is obtained through formula derivation and analysis, which realizes the coordinated optimization of emergency logistics infrastructure positioning and emergency rescue vehicle path positioning and minimizes the economic loss caused by the outbreak. Research data show that the robustness and sustainability of the port logistics system can help plan the shortest path between material supply locations. No problem in the logistics system is allowed to fail during this time period, so the robustness of a logistics system is very important. In the logistics transportation process, optimizing the shortest route and increasing the number of warehouse centers and the amount of stored materials will also decide the sustainable development of China's port logistics system [7].

\section{Proposed Method}

2.1. Architecture and Process of Emergency Logistics System. The emergency logistics system is composed of emergency command department, emergency logistics node, and emergency logistics information system [8]. The main work of the emergency command department is to consider the needs of emergency supplies, customize emergency logistics plans, make a backup support plan coordinated by various departments, adjust emergency logistics, and organize the information on the supply and demand of materials [9]. Emergency logistics nodes mainly include warehouses for emergency supplies, emergency distribution centers, rescue and transportation centers, and economic assistance stations [10]. The main task of the logistics node is to be responsible for the management of procurement, warehousing, transportation, distribution, recycling, and other aspects. The emergency logistics information system runs through all links in logistics. The main functions of the system are to save emergency-related resources, monitor real-time logistics dynamics, handle emergency events, and manage data [11]. The emergency logistics system process mainly includes procurement, warehousing, transportation, distribution, recycling, and other links. Each link is important to ensure that emergency supplies can be transported to the designated location in a timely and accurate manner, improve emergency equipment protection, and save costs $[12,13]$.

2.1.1. Emergency Logistics Procurement. When an epidemic occurs in an area, the reserves of emergency supplies are small and cannot meet the needs in front of the front [14]. Many daily supplies of daily supplies are not enough. In general, most supplies of living supplies and medical supplies do not promote storage. Therefore, emergency storage can be combined with actual item reserves and negotiated agreement reserves [15]. The signing of the agreement means that the civil affairs department signs the purchase agreement after consulting with the overseas company providing emergency supplies in advance; in case the epidemic situation suddenly comes, the contracted company quickly dispatches overseas resources to provide sufficient highquality materials [16]. This can not only reduce the series of expenses consumed for storing materials but also meet the material needs of the front line in time and avoid inflation caused by the shortage of materials.

2.1.2. Emergency Logistics Warehousing. Tianjin, Guangzhou, and other coastal cities need to be built into overseas epidemic emergency supplies storage bases, gradually increasing the number of emergency storage material warehouses and gradually forming a complete emergency logistics infrastructure [17]. In addition to tents, the types of storage materials should also increase the storage capacity of warehouses that use more materials during the period when epidemics spread such as medical materials and daily necessities. There are also optimization of storage capacity and professional equipment in warehouses, proper arrangement of storage plans, and optimization of warehouse space [18].

2.1.3. Emergency Logistics and Transportation. Various logistics companies need to set up emergency logistics transportation fleets to ensure sufficient capacity and reasonable coordination when the epidemic situation comes. After its establishment, it is necessary to conduct emergency drills from time to time to fully explore the stamina of transportation and, at the same time, pay attention to the connection between port material supply and transportation using GIS and GPS technology to control the emergency logistics transportation in real time and receive the latest developments at any time during the transportation of materials $[19,20]$. Relevant departments and people must cooperate to provide a "green channel" for emergency logistics and transportation and implement the principle of priority. The transportation department and the public security department are responsible for arranging the safety protection of emergency logistics transportation, timely handling of various problems that may occur in the transportation process, and providing safe transportation guarantee [21].

2.1.4. Emergency Logistics and Distribution. The emergency distribution center needs to be located in a convenient location around the epidemic area, and the space needs to be 
sufficient to ensure that the emergency supplies are smoothly loaded and unloaded. The distribution center is responsible for the recycling of emergency supplies for reuse [22]. After the epidemic has passed, return the position to the local emergency supplies storage warehouse. In addition, the distribution center must collect the types and quantities of the missing materials in detail and respond quickly and accurately to the emergency command department according to the epidemic situation and the lack of emergency supplies [23].

\subsubsection{Emergency Supplies Distribution Link. Reusable} emergency supplies such as tents need to be cleaned, repaired, and recycled on time. Relevant departments need to formulate recycling requirements to tell everyone to cherish the materials. The recovered materials are stored in emergency reserve warehouses at all levels of the government. Improving the recovery and repair quality of emergency supplies are the two most important requirements for handling materials. The entire process is shown in Figure 1.

\subsection{Countermeasures for the Development of China's Port Logistics}

2.2.1. Scientific Planning. Optimize China's port system. Only after detailed planning can the port resources be used rationally [3]. When using resources, extravagance or taste is avoided.

2.2.2. Taking Advantage of Development. Give play to the role of bonded areas. Full freedom is given to the company's asset size, capital investment, and business scope in the bonded zone, and the establishment of a bonded zone rule suitable for its own port is in line with overseas economic development.

2.2.3. Reasonable Layout. Speed up the construction of the port transportation network and adopt the waterway transportation method. Strengthen the construction of port hub railways. Improve the technical level of highway passages, properly allocate some materials to waterways and railways to prevent congestion of transportation passages, and ensure the sustainability of ports $[24,25]$.

2.2.4. Changing Roles. Constantly update the logistics service concept. Continuously create new products for discovery services, with a focus on accelerating the construction of logistics areas and taking service diversification as the focus of service innovation. To meet the needs of the public as the ultimate goal, China's port logistics system will be built into a new type of logistics center that mainly relies on modern transportation, integrating storage, packaging, distribution, processing, information services, and other service functions. The transportation node is transformed into a higher level logistics location [26].

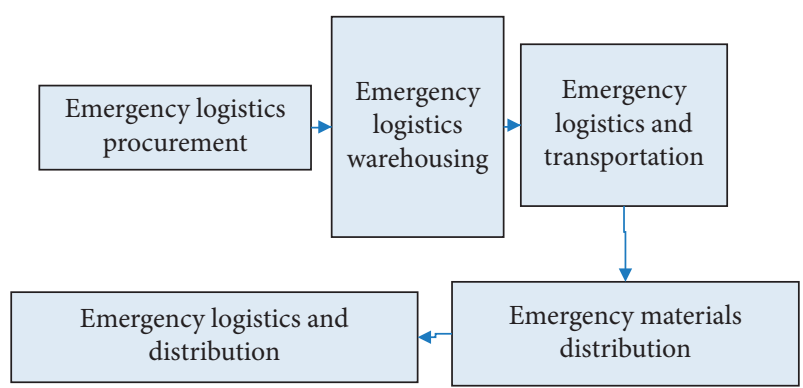

FIGURE 1: Emergency logistics system structure.

2.2.5. Scientific and Technological Innovation. Improve logistics technology and information level. Increase investment in the construction of information infrastructure, and at the same time, introduce cutting-edge technology from overseas [27]. Make full use of advanced information technology, establish a port logistics information network and a logistics public information communication platform, and formulate a unified port logistics system information standard as soon as possible so that the transport port has the function of logistics information, in order to provide better quality, efficient, and comprehensive port services in science and technology [28].

2.2.6. People-Oriented. Emphasis is provided on personnel training in the logistics service industry. It is necessary to increase investment in logistics professional colleges, especially in the fields of future work and port logistics enterprises. In addition to formal logistics courses offered by formal colleges and universities, enterprises train and educate employees within a certain period of time so that their professional knowledge can keep up with the development trend of the modern social logistics industry. In addition, the training of corporate leaders is also very important. Only if the corporate leaders accept the cutting-edge logistics concepts earlier than the employees can they lead the employees of his company to participate more actively in the reform and development of the enterprise and the logistics industry [29].

\subsection{LRP Robust Two-Layer Optimization Model for Emergency Logistics}

2.3.1. Structure of Problems in Emergency Logistics. The emergency logistics facility positioning-configuration problem (LAP) and emergency supplies transportation route selection problem (VRP) are two important places in the optimization design process of emergency logistics transportation system. LAP means that there are many demand points and alternative material equipment in a designated area. From each point, the location of the alternative material equipment points, the number of materials in each alternative material equipment point, and the corresponding demand can be determined. The distribution plan and VRP are mainly designed when the location of the candidate equipment location has been determined, and the vehicle transports the material route between the locations where 
each material is lacking so that it reaches the shortest total route or the lowest distribution cost [30]. Rescue emergency logistics equipment positioning-vehicle routing problem is simply considered to be the integration of LRP and VRP, which effectively integrates the attributes of LAP and VRP. By constructing a robust two-layer optimization model with uncertain coefficients in order to collaboratively optimize the port logistics system of emergency supplies, in this paper, the robust optimization method is used to establish the LRP of the port logistics system of emergency supplies with hierarchical correlation. The model was deterministically transformed, and a hybrid algorithm was designed to solve the transformed deterministic planning model below $[31,32]$.

The construction of the model relies on the following four assumptions:

(1) There are many places that need material support and material storage warehouses, and many rescue vehicles can be purchased.

(2) The rescue vehicles depart from their respective material storage warehouses and return to the original warehouses after successfully completing the delivery task.

(3) Any two material reserve warehouses are not on the same path.

(4) There is only one rescue vehicle for each place where supplies are needed.

2.3.2. Model Construction. In the context of uncertain requirements, a model with uncertain data is constructed as follows. The upper planning from the perspective of the logistics system as a whole, considering how to meet the warehouse storage capacity constraint conditions determine the total cost of LRP (logistics equipment positioning and purchase cost of different rescue vehicles, implement emergency warehouse construction costs, buy store supplies cost, purchase cost of rescue vehicles, and rescue vehicle fixed cost and shipping costs) to achieve a smaller one. Given the location of logistics equipment and the number of vehicles purchased. The lower planning only starts from the perspective of vehicle route planning and considers the minimization of operation cost and transportation cost within a specified time. In the upper and lower planning, $d_{r}(r \in G)$ is an undetermined parameter. Upper planning: consider the minimum cost of LRP from the perspective of port logistics system of emergency supplies. The decision variable:

$$
\begin{aligned}
F= & \min \sum_{i \in H} f_{i} x_{i}+\sum_{K \in V} \beta Q_{i}+\sum_{K \in V} g_{K} y_{K}+\sum_{K \in V} \sum_{i \in V} c_{K} z_{K i} \\
& +\sum_{g \in S} \sum_{h \in S} \sum_{K \in V} r_{K} l_{g h} w_{k g h} .
\end{aligned}
$$

(1) Objective Function. The lower-level planning minimizes the cost in the pursuit of vehicle path selection from a local perspective, mainly including the fixed operating cost and transportation cost of rescue vehicles:

$$
f=\min \sum_{K \in V} \sum_{i \in V} c_{K} z_{K i}+\sum_{g \in S} \sum_{h \in S} \sum_{K \in V} r_{K} l_{g h} w_{k g h} .
$$

(2) Constraints. The volume of materials transported to the demand point on the same route shall not be greater than that of the rescue vehicle:

$$
a \sum_{g \in S} \sum_{h \in S} \sum_{i \in H} w_{k g h} K_{r} \leq y_{K} q_{K}, \quad \forall K \in V .
$$

The driving distance limit of rescue vehicles is

$$
\sum_{g \in S h \in S} \sum_{g h} w_{k g h} \leq \operatorname{dis}_{K}, \quad \forall K \in V .
$$

Formula (5) guarantees that the selected warehouse has vehicles to send out, formula (6) guarantees that the unselected warehouse cannot send out, and formula (7) guarantees that the rescue vehicles can only be allocated to the selected warehouse:

$$
\begin{gathered}
\sum_{r \in G} \sum_{K \in V} w_{k i r}-x_{i} \geq 0, \quad \forall k \in V, \\
\sum_{r \in G} w_{k i r}-x_{i} \leq 0, \quad \forall k \in V, \\
z_{k i} \leq x_{i}, \quad \forall i \in H, \forall k \in V .
\end{gathered}
$$

The following formula indicates that the path of each vehicle is only issued from the warehouse:

$$
\sum_{r \in G} w_{k i r}=z_{k i}, \quad \forall i \in H, \forall k \in v
$$

The following formula represents two selected warehouses that are not on the same path:

$$
\sum_{k \in V} w_{k g h}=1, \quad \forall g, h \in H
$$

The exit point of each vehicle must be the vehicle's entry point, as shown in formula (10). Considering that the arrival time of materials cannot be determined, the parameters $t_{k g h}$ can be assumed to be indeterminate data in this model:

$$
\sum_{k \in V} w_{k h g}-\sum_{k \in V} w_{k g h}, \quad \forall k \in V, \forall k \in S .
$$

\section{Experiments}

3.1. Experimental Background. Since the model established above takes into account the unresolvable data of the demand for emergency supplies, it is assumed that the demand for materials in locations where the materials are lacking fluctuates within the box set. However, when an epidemic occurs, the road network is often damaged, affecting the time when the rescue vehicles actually deliver the emergency relief materials. Therefore, this experiment is based on the 
optimization model and then improved according to the actual measurement situation.

3.2. Source of Experimental Data. The experimental data select the basic experiment carried out by a port in Tianjin. Firstly, the relationship between the decision variables of logistics location and the decision variables of the path selection of rescue vehicles is established to establish a statistical model, and then, LAP and VRP are used for simulation. Randomly select 3 places as alternative emergency supplies distribution centers in the 100 data of the country, get three random numbers in the range of 1-99, and use these 3 numbered positions as alternative emergency supplies distribution in this calculation example The position of the center, simulating the situation of the vehicle, and the travel time of the vehicle between the points all follow the normal distribution, and the average speed of the vehicle on the way is $60 \mathrm{~km} / \mathrm{h}$. In LAP, the alternative material transportation and tour routes from the location of the material equipment to the place where the material is needed are all radial. Each alternative material equipment location transportation vehicle needs to be responsible for the alternative material transportation in multiple material shortage locations. After the transportation is completed from the alternative material facility point and returned to the nearby material facility point, this fully considers the material vehicle tour route planning using simulation models and field operations to verify the port logistics system and sustainability of the outbreak emergency from overseas.

3.3. Experimental Setup. This experiment aims at the two interconnected problems of emergency logistics equipment positioning and rescue vehicle route in the emergency logistics system. Considering that it is difficult to accurately grasp the exact epidemic occurrence area and the corresponding area's demand for materials in emergencies, the model optimizes LAP and VRP together. Although there is a relationship between the decision variables of logistics site location and the decision variables of rescue vehicle routing, there is also a sequence of decisions for the two. In the established bilevel planning model, the leading role of facility positioning decision is emphasized. To put it simply, the location decision of emergency equipment greatly affects the vehicle road planning for the rescue epidemic, and the vehicle path planning also affects the location of emergency facilities. But the positioning decision of emergency equipment has always been a priority.

The steps are as follows:

(1) The planning of the upper layer starts from the perspective of the overall emergency logistics system, and the pursuit of LRP costs should be reduced to the greatest extent.

(2) The lower-level planning is only from the perspective of vehicle route planning [33], plus the consideration of minimizing transportation costs, so as to achieve the overall optimization of port logistics equipment positioning and rescue vehicle route planning for epidemic emergency supplies from overseas as a whole and to minimize the losses caused by the epidemic.

(3) Next, the data measured by the actual situation are used to verify the practicality and transportation effect of the optimized transportation efficiency of the robust system.

\section{Discussion}

4.1. Logistics Analysis. From the data in Table 1 and Figure 2, it can be seen that the optimized formula of the port point under different serial numbers theoretically solves the two interrelated problems of emergency logistics equipment positioning and rescue vehicle route in the emergency logistics system, but it has not been used in real situations. Therefore, this article will use the data in the simulation of real-life training to test whether the optimized port logistics system and sustainability research have ensured the outbreak emergency response from overseas.

Randomly select 3 places from the 100 data of RC208 as candidate emergency supplies distribution centers, obtain 3 random numbers in the range of $1-99$, and use these 3 numbered positions as the example alternative emergency supplies distribution center location. The data in Table 2 are mainly based on the RC208 in the RC type question bank, and based on the robustness and sustainability of the port logistics system of epidemic emergency supplies from overseas studied in this article, it supplements the fluctuation ratio of demand. Randomly choose 3 places from the 100 data of RC208 as alternative emergency supplies distribution centers, get three random numbers in the range of 1 to 99 , and use these 3 numbered positions as alternative emergency in the calculation example of the location of the material distribution center. In a similar way, we can obtain data on 15 locations where emergency supplies are missing. As shown in Table 2, the time windows in nos. 1-20 are controlled between $[0,600]$, and the demand of each demand location fluctuates within the box set, where the data of $d *$ are shown in Table 2 and Figure 3, by calculating the demand fluctuation ratio of $6.5 \%$.

4.2. Material Analysis. Assume that there are 5 vehicles of 2 types each as shown in Table 3, all of which are 9 yuan $/ \mathrm{km}$. When dealing with random delivery time, this paper will follow the normal distribution of the travel time of vehicles between each point. The average traveling speed of vehicles on the way is $60 \mathrm{~km} / \mathrm{h}$. In LAP, the alternative material transportation and tour routes from the location of the material equipment to the place where the material is needed are all radial. Each alternative material equipment location transportation vehicle needs to be responsible for the alternative material transportation in multiple material shortage locations. After the transportation is completed from the alternative material facility point and returned to the nearby material facility point, this fully considers the material vehicle tour route planning solves the problem of 
Table 1: Port logistics system data.

\begin{tabular}{lcccc}
\hline Serial number & $X$ coordinate $(\mathrm{km})$ & $Y$ coordinate $(\mathrm{km})$ & Capacity (piece) & The construction of running \\
\hline A & 50 & 10 & 1510 & 25 \\
B & 53 & 70 & 1900 & 30 \\
C & 21 & 65 & 1900 & 25 \\
\hline
\end{tabular}

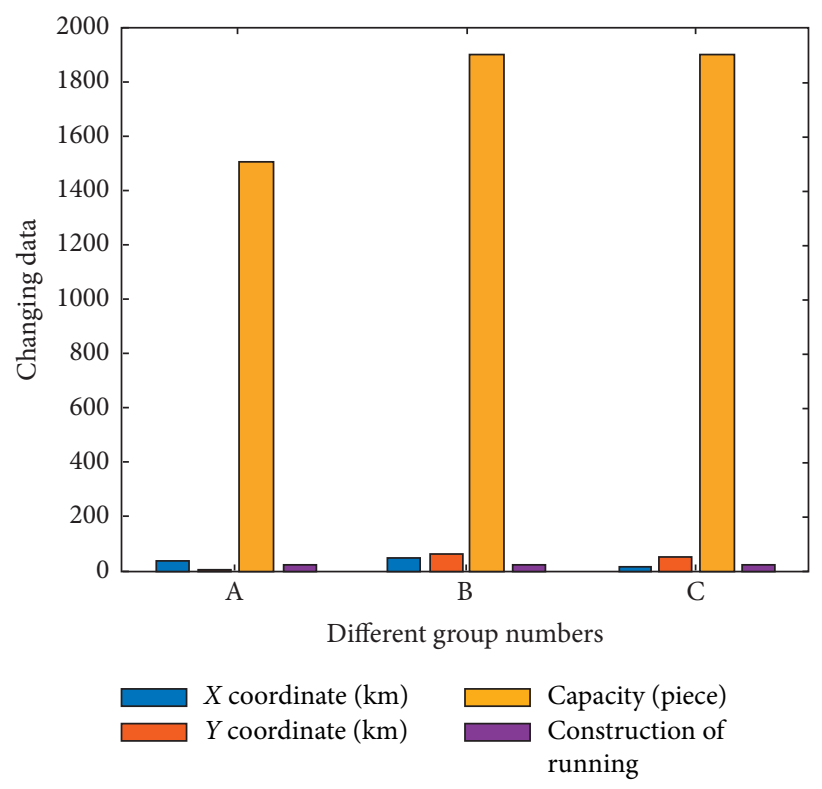

Figure 2: Port logistics system data.

TABle 2: Data of emergency supplies demand points.

\begin{tabular}{|c|c|c|c|c|c|c|}
\hline Serial number & $X$ coordinate $(\mathrm{km})$ & $Y$ coordinate $(\mathrm{km})$ & Demand 1 (piece) & Demand 2 (piece) & Demand 3 (piece) & Time window $(\mathrm{m})$ \\
\hline 1 & 20 & 80 & 130 & 130 & 150 & {$[0.520]$} \\
\hline 2 & 6 & 45 & 369 & 375 & 388 & {$[0.560]$} \\
\hline 3 & 44 & 20 & 65 & 80 & 84 & {$[0.515]$} \\
\hline 4 & 40 & 25 & 140 & 153 & 165 & {$[0.534]$} \\
\hline 5 & 90 & 30 & 128 & 138 & 153 & {$[0.535]$} \\
\hline 6 & 83 & 25 & 69 & 78 & 82 & {$[0.555]$} \\
\hline 7 & 62 & 80 & 180 & 198 & 212 & {$[0.591]$} \\
\hline 8 & 80 & 60 & 129 & 135 & 150 & {$[0.569]$} \\
\hline 9 & 56 & 82 & 65 & 75 & 82 & {$[0.520]$} \\
\hline 10 & 30 & 80 & 270 & 275 & 282 & {$[0.550]$} \\
\hline 11 & 20 & 30 & 60 & 70 & 74 & {$[0.575]$} \\
\hline 12 & 15 & 10 & 130 & 136 & 142 & {$[0.568]$} \\
\hline 13 & 46 & 46 & 62 & 70 & 78 & {$[0.600]$} \\
\hline 14 & 65 & 30 & 245 & 252 & 257 & {$[0.520]$} \\
\hline 15 & 30 & 50 & 165 & 178 & 186 & {$[0.527]$} \\
\hline 16 & 2 & 60 & 40 & 45 & 50 & [0.538] \\
\hline 17 & 5 & 6 & 100 & 111 & 120 & {$[0.561]$} \\
\hline 18 & 57 & 35 & 120 & 135 & 135 & {$[0.506]$} \\
\hline 19 & 6 & 16 & 160 & 168 & 169 & {$[0.506]$} \\
\hline 20 & 25 & 35 & 296 & 305 & 305 & {$[0.256]$} \\
\hline
\end{tabular}

time and total distance of transportation. The robustness and sustainability of the port logistics system saves the time of the entire process by about $45 \%$ so that transportation costs and economic pressure will be greatly reduced. In VRP, the coordination characteristics of the transportation vehicles to the transportation of various material vehicles and the transportation of the materials and the locations of the tour routes have been fully considered; that is, the efficiency of emergency supplies transportation is improved, and it is in line with the actual situation. During this process, the 


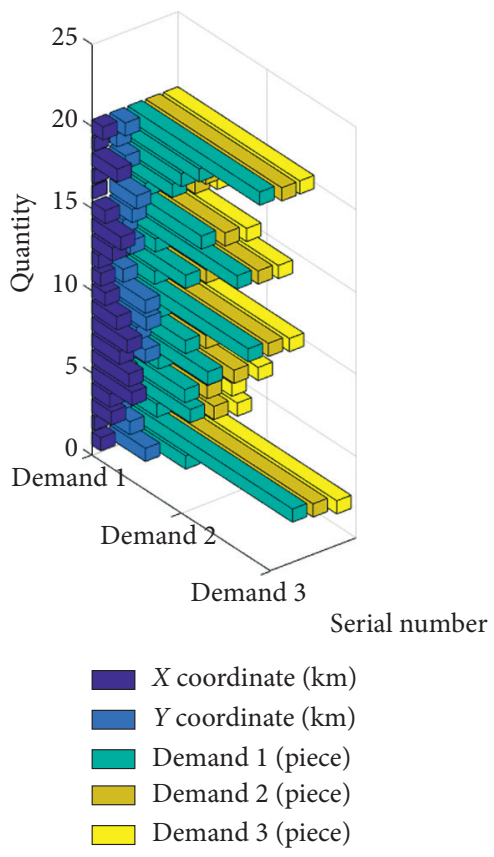

Figure 3: Data of emergency supplies demand points.

TABle 3: Data from emergency supplies vehicles.

\begin{tabular}{lcccc}
\hline Vehicle number & Capacity (piece) & Purchase cost (yuan) & Fixed cost (yuan) & Maximum range (km) \\
\hline $1-5$ & 100 & 200000 & 500 & 350 \\
$6-10$ & 155 & 350000 & 600 & 360 \\
\hline
\end{tabular}

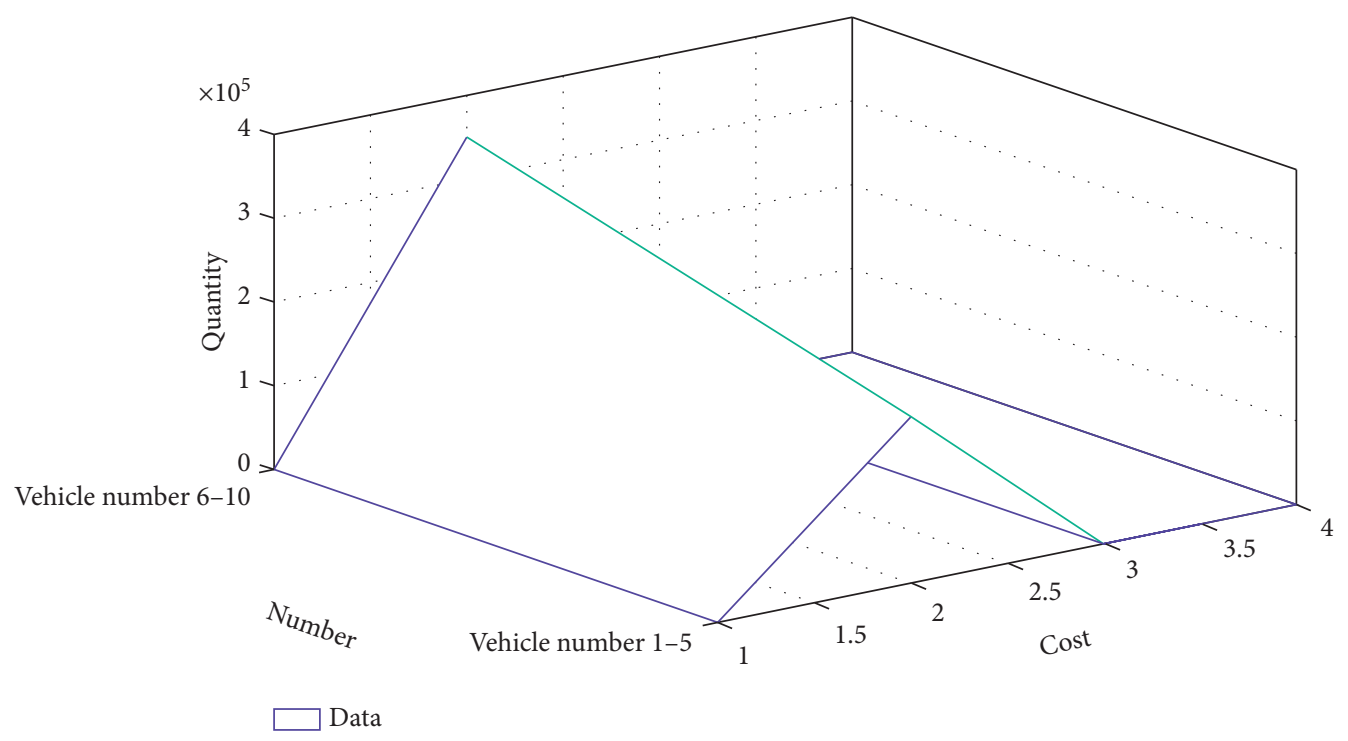

FIGURE 4: Data from emergency supplies vehicles.

transportation vehicle has accurately positioned the material facilities so that the entire logistics cost reaches the minimum. Specific data are shown in Table 3 and Figure 4.

This experiment stipulates a series of material shortage locations and alternative material equipment locations that are consistent with the actual rescue problem within the specified range. It can be seen from Table 4 and Figure 5 that the number and time of the planned road map, from which to choose the largest number, the best location, the largest material capacity of the material setting location, and to determine the best material, is missing the location of the material distribution and simple and specific transportation schemes and, at the same time, rationally arrange the corresponding best material transportation plans and 
TABLE 4: Location, distribution vehicles, and route selection.

\begin{tabular}{lcc}
\hline $\begin{array}{l}\text { Alternative distribution } \\
\text { center number }\end{array}$ & Vehicle number & $\begin{array}{c}\text { Corresponding } \\
\text { distribution route }\end{array}$ \\
\hline A & 4 & A-6-5-14-A \\
& 9 & A-12-19-17-A \\
& 10 & A-4-3-18-A \\
B & 6 & B-9-1-10-16-2-B \\
& 7 & B-8-7-B \\
\hline
\end{tabular}

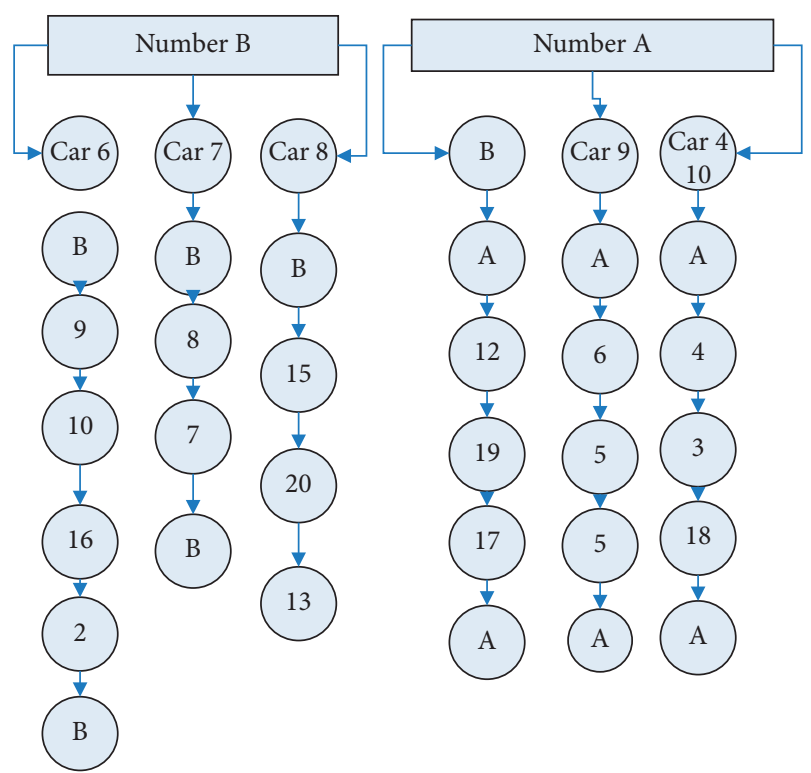

FIGURE 5: Location, distribution vehicles, and route selection.

alternative roads with shorter distances according to needs. In a real situation, you can make full use of the relationship between the two to better solve the problem and quickly formulate all corresponding response measures. The entire specific data are shown in Table 4 and Figure 5.

\section{Conclusions}

(1) Based on the study of port logistics system problems, this paper considers the optimization problems of LAP and VRP in the logistics system, as well as the uncertainty of the demand that exists in the port emergency logistics system, and emphasizes the premise of equipment positioning planning as a guide. Next, the optimized model is constructed based on the model. Among them, the upper level planning pursues the reduction of the maximum scope of LRP cost from the perspective of the port logistics system of emergency supplies. Under the conditions of the given logistics equipment location and the number of different rescue vehicles purchased, the lower-level planning only pursues the operation cost and transportation cost to the minimum when meeting the prescribed time from the perspective of vehicle driving route selection. The algorithm in the paper is used to answer the converted bilevel programming model with determinable parameters, so as to finally obtain a robust solution to the LRP problem of the emergency logistics system under uncertain conditions and realize the location of emergency logistics equipment and rescue vehicles. The roads are optimized to minimize the losses caused by sudden outbreaks and to maintain the robustness and sustainability of the port logistics system from overseas outbreak emergency logistics.

(2) Because the epidemic situation and the location of the epidemic situation are unpredictable, the location of the epidemic situation is uncertain about the location and demand for rescue emergency supplies and facilities. After the outbreak, the transportation efficiency of emergency supplies plays an important role in the rescue process. In this paper, during the process of emergency logistics mobilization and material delivery, the problem of slow dispatching time or insufficient inventory supply in the warehouse, which leads to insufficient rescue capabilities, is solved to the greatest extent. In addition, the risks in the emergency logistics process are random and may exist in a certain link. If one link destroys the entire emergency logistics system, it may be destroyed and causes greater losses. In the process of risk spreading, the improvement of the resilience of nodes in the region has a greater impact on risk spreading than the increase in the level of risk infection. Therefore, it is necessary to strengthen the reliability of its own material retention, attach importance to external communication, and ensure the smooth access of rescue channels. The increase in rescue speed has a good inhibitory effect on the spread of risks. The effectiveness of rescue speed should be considered. Excessive rescue will weaken the effect of controlling the spread and spread of risks.

(3) This paper analyzes the sustainable development capability of the port logistics system from overseas epidemic emergency supplies and formulates coping strategies and robust collaborative optimization methods. The optimized and robust system is obtained through formula derivation and analysis, which realizes the coordinated optimization of emergency logistics infrastructure positioning and emergency rescue vehicle path positioning and minimizes the economic loss caused by the outbreak. Research data show that the robustness and sustainability of the port logistics system can help plan the shortest path between material supply locations. The research results show that the proportion of demand fluctuations during the outbreak is $6.5 \%$, the time window needs to be controlled between 0 and 600 , and the robustness and sustainability of the port logistics system has saved the time of the entire process by about $45 \%$, greatly optimizing the delivery route and delivery time, and the robustness of the 
logistics system can be widely used in emergency events.

\section{Data Availability}

The data in the article are actually available.

\section{Conflicts of Interest}

The authors declare that there are no conflicts of interest in our paper.

\section{Acknowledgments}

This work was supported by the Jinhua City Federation of Social Sciences (No. YB2020060) and Jinhua City Bureau of Commerce 2020 Jinhua City E-commerce Work Research Project "Turning Crisis into Opportunity: Countermeasures and Suggestions for SMEs in Jinhua City to Resume Work and Production by Digital Trade under the Globalization of the Epidemic" (No. 22), Zhejiang Province in China.

\section{References}

[1] Q. Qu, K. Y. Chen, Y. M. Wei, Y. Liu, S. B. Tsai, and W. Dong, "Using hybrid model to evaluate performance of innovation and technology professionals in marine logistics industry," Mathematical Problems in Engineering, vol. 2015, Article ID 361275, 8 pages, 2015.

[2] Y. C. Wu and S. J. Y. Zhao, "Supply chain management theory and its application in animal livestock logistics," Revista Cientifica-Facultad De Ciencias Veterinarias, vol. 29, no. 1, pp. 43-51, 2019.

[3] J. D. Vanvactor, "Healthcare logistics in disaster planning and emergency management: a perspective," Journal of Business Continuity \& Emergency Planning, vol. 10, no. 2, pp. 1-20, 2017.

[4] J. Guo, J. Pan, J. Guo, F. Gu, and J. Kuusisto, "Measurement framework for assessing disruptive innovations," Technological Forecasting \& Social Change, vol. 139, pp. 250-265, 2018.

[5] S. Mustari, "Strategic port management - between tradition and reform," Jurnalul De Studii Juridice, vol. 1-2, no. 1-2, pp. 123-132, 2018.

[6] V. Mirzabeiki, P. V. Sjöholm, and Per Sjöholm, "Collaborative tracking and tracing applied on dry ports," International Journal of Logistics Systems and Management, vol. 25, no. 3, p. 425, 2016.

[7] L. R. d. O. Andr eacute a and d. O. M. C. Lucas, "Evaluating the logistics performance of Brazils corn exports: a proposal of indicators," African Journal of Agricultural Research, vol. 11, no. 8, pp. 693-700, 2016.

[8] C. Nguyen and T. Notteboom, "Dry ports as extensions of maritime deep-sea ports: a case study of vietnam," Journal of International Logistics and Trade, vol. 14, no. 1, pp. 65-88, 2016.

[9] A. K. Y. Ng, Z. Yang, S. Cahoon, and P. T.-W. Lee, "Introduction: port, maritime logistics, and regional development," Growth and Change, vol. 47, no. 3, pp. 346-348, 2016.

[10] T. G. Péra and J. V. Caixeta-Filho, "Impact of vertically integrated road transport on Brazilian sugar export logistics: a mathematical programming application," International Business Research, vol. 9, no. 12, p. 85, 2016.
[11] A. Suárez-Alemán, T. Serebrisky, and O. Ponce de León, "Port reforms in Latin America and the Caribbean: where we stand, how we got here, and what is left," Maritime Economics \& Logistics, vol. 20, no. 4, pp. 495-513, 2018.

[12] R. Mangiaracina, A. Perego, and G. Salvadori, "A comprehensive view of intelligent transport systems for urban smart mobility[J]," International Journal of Logistics, vol. 20, no. 1, pp. 1-14, 2016.

[13] R. D. Soliani and P. P. d. S. Guedes, "Logistics aspects of transport modalities on the exports of raw sugar," European Scientific Journal, ESJ, vol. 12, no. 16, pp. 345-362, 2016.

[14] G. Zhang and B. Zhang, "Optimization model of emergency medical supplies dispatching," Investigacion Clinica, vol. 60, no. 3, pp. 603-608, 2019.

[15] Y. Gu and S. Gao, "Analysis on the logistics cost control of self-logistics system in the electric business enterprise," American Journal of Industrial and Business Management, vol. 6, no. 12, pp. 1113-1121, 2016.

[16] X. Huang and L. Song, "An emergency logistics distribution routing model for unexpected events," Annals of Operations Research, vol. 269, no. 6, pp. 1-17, 2018.

[17] H. Zhao, C. Niu, T. Zhang, and S. Cai, "Review and prospect of emergency logistics under uncertainty conditions," Journal of Risk Analysis and Crisis Response, vol. 8, no. 2, p. 101, 2018.

[18] M. Benabdouallah, C. Bojji, and O. E. Yaakoubi, "Sector prioritisation in Rabat region for emergency management," International Journal of Emergency Management, vol. 14, no. 1, p. 1, 2018.

[19] J. Clarke, J. A. V. Gascon, and J. A. Ferland, “A capacitated vehicle routing problem with synchronized pick-ups and drop-offs: the case of medication delivery and supervision in the DR Congo," IEEE Transactions on Engineering Management, vol. 64, no. 3, pp. 327-336, 2017.

[20] A. M. Eassa, M. Elhoseny, M. Hazem, El-Bakry, and A. S. Salama, "NoSQL injection attack detection in web applications using RESTful service," Programming and Computer Software, vol. 44, no. 6, pp. 435-444, 2018.

[21] V. K. Senthil Ragavan, M. Elhoseny, and K. Shankar, "An enhanced whale optimization algorithm for vehicular communication networks," International Journal of Communication Systems, Article ID e3953, 2019.

[22] J. Meng, "Teaching research and practice of logistics management," Journal of Jilin Education Institute, vol. 32, no. 11, pp. 98-100, 2016.

[23] D. Hrušecká, M. Pivnička, and R. B. Lopes, "Logistics management as a system constraint," Polish Journal of Management Studies, vol. 15, no. 1, pp. 76-87, 2017.

[24] M. V. Kajresheva, "The system of effective management of transport and logistics company," Proceedings of the Voronezh State University of Engineering Technologies, vol. 79, no. 1, pp. 432-437, 2017.

[25] T. Gaber, S. Abdelwahab, M. Elhoseny, and A. E. Hassanien, "Trust-based secure clustering in WSN-based intelligent transportation systems," Computer Networks, vol. 146, pp. 151-158, 2018.

[26] G. Jie and Z. Mingliang, "Internet of things management mode and multi-dimensionally collaborative evaluation method for agricultural product logistics service," International Journal of Smart Home, vol. 10, no. 10, pp. 1-8, 2016.

[27] Z. Lv, B. Hu, and $\mathrm{H}$. Lv, "Infrastructure monitoring and operation for smart cities based on IoT system," IEEE Transactions on Industrial Informatics, vol. 16, no. 3, pp. 1957-1962, 2020. 
[28] U. Sallnäs, "Coordination to manage dependencies between logistics service providers and shippers," International Journal of Physical Distribution \& Logistics Management, vol. 46, no. 3, pp. 316-340, 2016.

[29] H. Fu, "Integration of logistics simulation technology and logistics learning factory in a two-stage teaching method for logistics management courses," International Journal of Emerging Technologies in Learning (iJET), vol. 12, no. 9, p. 62, 2017.

[30] M. Giuffrida, R. Mangiaracina, and A. Perego, "Cross border B2C e-commerce to Greater China and the role of logistics: a literature review," International Journal of Physical Distribution \& Logistics Management, vol. 47, no. 6, 2017.

[31] V. Santén, "Towards more efficient logistics: increasing load factor in a shipper's road transport," The International Journal of Logistics Management, vol. 28, no. 2, pp. 228-250, 2017.

[32] W. J. Rose, D. A. Mollenkopf, C. W. Autry, and J. E. Bell, "Exploring urban institutional pressures on logistics service providers," International Journal of Physical Distribution \& Logistics Management, vol. 46, no. 2, pp. 153-176, 2016.

[33] S. Wan, X. Li, Y. Xue et al., "Efficient computation offloading for Internet of vehicles in edge computing-assisted $5 \mathrm{G}$ networks," The Journal of Supercomputing, vol. 76, no. 4, 2019. 